\title{
Aspectos éticos nas redes sociais de apoio no cuidado domiciliar à luz do pensamento complexo
}

Recebido em: 20/12/2012

Aceito em: 12/07/2012
Ingrid Meireles Gomes Luciane Faver ${ }^{2}$ Ana Paula Hermann ${ }^{3}$ Maria Ribeiro Lacerda ${ }^{4}$

Ensaio reflexivo sobre aspectos éticos que permeiam as redes sociais de apoio no cuidado domiciliar, sob o referencial da complexidade de Edgar Morin. Aspectos éticos discutidos: possibilidade de ampliação da cidadania dos sujeitos; transmissão de informações relevantes ao processo saúde-doença; e inter-relações - sujeito, família, profissional e sistema. Constatou-se que sujeito, família e profissionais podem ser considerados unidades complexas que, ao se articularem e organizarem, formam um sistema a ser compreendido na relação que mantêm com o ambiente e o tempo.

Descritores: Cuidados Domiciliares de Saúde, Apoio Social, Ética.

\section{Ethical Aspects in social networks support in home care at the light of complex thought}

Reflective essay about ethical aspects that permeate support social networks in home care, beneath the reference of Edgar Morin's complexity. Ethical aspects discussed: possibility of expansion of citizenship of people; relevant information transmission to the health-disease process; and person, family, professional and system interrelationships. It was noted that subject, family and professionals should be considered complex units and that when they join and organized themselves, they form a system that will be understood in the relation that keep with environment and time.

Descriptors: Home Nursing, Social Support, Ethics.

\section{Cuestiones éticas en las redes de apoyo social en la perspectiva de la atención domiciliaria del pensamiento complejo}

Ensayo reflexivo sobre aspectos éticos que permean redes sociales de apoyo en el cuidado domiciliario, bajo el referencial teórico de la complejidad de Edgar Morin. Aspectos éticos abordados: posibilidad de ampliación de la ciudadanía de los sujetos; transmisión de informaciones relevantes al proceso salud-enfermedad; y las interrelaciones - sujeto, familia, profesional y sistema. Se encontró que sujeto, familia y profesionales pueden ser considerados unidades complejas que, cuando se articulan y organizan, forman un sistema que debe ser entendido en la relación con ambiente y tiempo.

Descriptores: Atención Domiciliaria de Salud, Apoyo Social, Etica.

\section{INTRODUÇÃO}

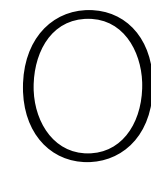
cuidado domiciliar (CD) retrata um movimento significativo de reordenação do modelo de atenção em saúde nacional(1). Possui vantagens de gerar economia, maior rotatividade nos leitos hospitalares, humanização do cuidado, ampliação da autonomia e privacidade dos sujeitos, além de considerar a relação enfermeiro-sujeito/família como uma coparticipação(2).

Atuar profissionalmente no domicílio requer conhecimento das peculiaridades desta modalidade de assistência à saúde: equipe interdisciplinar, contexto domiciliar, indivíduo, família, cuidador e redes sociais de apoio ${ }^{(3)}$. Essas últimas representam instrumentos potencializadores do trabalho da enfermagem no $C D$, mais que o repasse de recursos de diferentes fontes, influenciam na conservação da saúde dos sujeitos, e geram empoderamento frente ao adoecimento ${ }^{(4)}$.

Dentre as vantagens das redes sociais de apoio encontram-se proteção fisiológica, psicológica e social, conversão à cidadania, maior possibilidade de satisfação das necessidades materiais, financeiras, emocionais ou de informação ${ }^{4}$. Particularmente no $\mathrm{CD}$, proporciona maior adaptação dos sujeitos às alterações no modo de vida ${ }^{(4)}$.

Redes sociais de apoio e $C D$ têm influências significativas e definitivas ao se inter-relacionarem como possibilidade de alcance da saúde do sujeito e seu entorno. Compreender essa conexão permite pensar sobre aspectos éticos existentes; principalmente quando se percebe que o avanço da ciência e tecnologia não se segue de avanços existenciais e éticos ${ }^{(5)}$.

Visto que ética e saúde têm como matriz o envolvimento

1 Mark. Enfermeira. Mestranda do Programa de Pós-Graduação em Enfermagem da Universidade Federal do Paraná PPGENF/UFPR. Membro do Núcleo de Estudos, Pesquisa e Extensão em Cuidado Humano em Enfermagem - NEPECHE/UFPR. E-mail: inguide@gmail.com 2 Enfermeira. Doutoranda do PPGENF/UFPR. Membro do NEPECHE/UFPR. Bolsista CAPES/DS. 3 Enfermeira. Doutoranda do PPGENF/UFPR. Membro do NEPECHE/UFPR. Bolsista CAPES. 4 Enfermeira. Doutora em Enfermagem pela Universidade Federal de Santa Catarina. Docente do PPGENF/UFPR. Líder do NEPECHE/UFPR. Pesquisadora CNPq. 
em interações e associações, a saúde pode ser vivenciada sob a perspectiva de potencializar relações entre seres humanos em harmonia conflituosa, que possibilita o vir a ser ético nos múltiplos modos de ser e viver ${ }^{(6)}$. Nessa perspectiva, objetivase realizar um ensaio reflexivo acerca dos aspectos éticos que permeiam as redes sociais de apoio no CD sob o referencial da complexidade de Edgar Morin, que propõe a reforma do pensamento para alcançar a ética do gênero humano.

Morin exalta a importância do: contexto global, multidimensional e complexo, como promotores da inteligência geral; trabalha a ideia de unidade e diversidade humana ${ }^{(7-8)}$. Esse referencial reconhece que o ser humano traz características antagonistas de modo bipolarizado, e, portanto, é um ser complexo $^{(7-8)}$. Três princípios podem auxiliar a compreensão da complexidade: princípio dialógico, recursão organizacional e hologramático ${ }^{(9)}$, os quais serão abordados no decorrer deste ensaio.

Para discutir questões éticas, deve-se considerar a complexidade que lhe é inerente, a fim de propor uma ética da compreensão e solidariedade - antropoética, que compreende a completude humana, com consciência e cidadania planetária ${ }^{(6-7)}$. Para tal, considera-se, como proposto por Morin, o caráter tríplice da condição humana, indivíduo-sociedade-espécie, que, para se desenvolver faz-se necessário desenrolar, conjuntamente, autonomia individual, participação comunitária e consciência de pertencer à espécie humana ${ }^{(7-8)}$.

Diferentes aspectos podem se relacionar às temáticas aqui refletidas, mas dada a vivência das autoras, optou-se por trabalhar os itens: possibilidade de ampliação da cidadania dos sujeitos; transmissão de informações relevantes ao processo saúde-doença; e inter-relações - sujeito, família, profissional e sistema.

\section{POSSIBILIDADE DE AMPLIAÇÃO DA CIDADANIA DOS SUJEITOS}

Cidadania pode ser entendida como "processo de ação social no qual os sujeitos tomam posse de suas próprias vidas pela interação com outros sujeitos, gerando pensamento crítico em relação à realidade" e, com isso, construir a capacidade social e pessoal e transformar as relações de poder (10:928).

Globalização, capitalismo e distanciamento das relações levam a sociedade na contramão do sentido de redes, de interdependência e solidariedade ${ }^{(10)}$. Isso pode criar nos sujeitos uma sensação de exclusão da rede social e dos processos decisórios. Estes, quando participam de redes sociais de apoio, acabam por estreitar e ativar relações sociais, além de se moverem em torno de um ideal comum e cooperar entre si ${ }^{(10)}$.

No âmbito social da saúde, essas redes exercem importante papel para romper o isolamento individual e melhorar as condições dos sujeitos ${ }^{(10)}$ ao viabilizar participação ativa no processo do cuidado com sua saúde. Isso é percebido principalmente no $C D$, em que nas relações de poder, diferentemente do espaço hospitalar, sujeito e família não estão em situação de submissão(11).

Há que se pensar nos aspectos relacionados à cidadania para além do individual, como o empoderamento comunitário, que ocorre, entre outros fatores, pelo fortalecimento das redes sociais em busca de seus direitos e pela participação efetiva da população, em especial no CD, a fim de apontar problemas e soluções capazes de garantir avanços na qualidade dos serviços de saúde ${ }^{(10,12)}$

A participação social representa uma forma de fortalecer o senso de responsabilidade e solidariedade, ou seja, cidadania. É necessário uma aprendizagem cidadã, ter ciência de que vivemos na mesma comunidade de destino, seja pela exposição às mesmas ameaças mortais, pela identidade humana comum, homo sapiens, ou pela origem terrestre ${ }^{(8)}$.

Além do direito à saúde, cabe à população, como dever conhecimento dos serviços e participação efetiva no planejamento e avaliação das ações, garantindo esse direito ${ }^{(13)}$. Assim, pode-se dizer que há uma relação dialógica entre direito e dever, fenômenos indissociáveis e necessários um ao outro na sociedade. Demonstrado o princípio dialógico que "une dois princípios ou noções que deviam excluir-se reciprocamente, mas são indissociáveis em uma mesma realidade" ${ }^{\prime(8: 95)}$.

Ao assumir deveres, dá-se o primeiro passo para a consciência terrena, sentimento de pertencimento mútuo e ressalta a necessidade de que se aprenda a ser, viver, dividir e comunicar, e que os humanos possam condicionar, melhorar e compreender sua existência(7).

Ter consciência terrena não é responsabilidade exclusiva do sujeito, os profissionais de saúde também devem tê-la. Particularmente no âmbito domiciliar, espera-se que o profissional, mais que intervir na dimensão biológica do adoecimento, desenvolva práticas inovadoras de construção da saúde, na prevenção e promoção ou na possibilidade de uma finitude serena.

O profissional pode atuar como potencializador da cidadania dos sujeitos em CD. Para tal, evidencia-se a importância de articular ações de educação em saúde como elemento produtor do saber coletivo que traduz no sujeito autonomia e emancipação para o cuidar de si, da família e do seu entorno ${ }^{(12,14)}$. Contudo, a ação dos profissionais será potencializadora se for uma ação respeitosa, que aceite o direito da tomada de decisão e a capacidade de ação autônoma das pessoas.

Ademais, deve-se considerar o CD como facilitador no enfrentamento da situação de adoecimento, pois possibilita a efetivação do princípio ético de respeito à autonomia. Entendendo-a como substancial, o sujeito passa por menores constrangimentos dado o ambiente propício - o lar, mas ainda sofre influências externas em sua melhora ${ }^{(14)}$. 
$O$ respeito à autonomia dos sujeitos em $C D$ é fundamental, mas há que se considerar as limitações existentes - condições psicológicas e legais na tomada de suas próprias decisões. Significa, em determinadas circunstâncias, sobrepujar o respeito pela autonomia por outras obrigações morais, "como no caso das escolhas autônomas dos sujeitos ameaçarem a saúde pública, poderem causar danos a terceiros ou demandarem indevidamente a utilização de recursos escassos" (14:57). Portanto, autonomia não significa liberdade absoluta, pois depende do ambiente biológico, social ou cultural ${ }^{8}$.

\section{TRANSMISSÃO DE INFORMAÇÕES RELEVANTES AO PROCESSO SAÚDE-DOENÇA}

No domicílio, por suas peculiaridades e pela coparticipação dos sujeitos, é necessário atentar para o tipo de informação repassada pelos profissionais, sobre a forma como é transmitida, se escrita ou oral, e se foi fornecida ao sujeito, igual ou não, àquela ofertada aos familiares ${ }^{(15)}$.

Nesse cenário, informação é uma forma de apoio. Àqueles que as fornecem cabe a função de contextualizá-las, conscientes da inseparabilidade deste novo saber ao ambiente cultural, social, econômico e natural, ou seja, estimular um pensamento ecologizante ${ }^{(8)}$.

A transmissão de informações nas redes é positiva, pois auxilia na melhora e ampliação do conhecimento do sujeito sobre sua situação e representa um dos diversos tipos de apoio que as redes podem ofertar ${ }^{(10)}$. Por isso, o profissional atuante no $C D$ precisa buscar, junto aos sujeitos, retorno sobre o envolvimento em redes de apoio, verificar os conhecimentos adquiridos, para continuar a orientar e acompanhar o caso enquanto for necessário, e a funcionalidade da rede, para continuar ou não a referenciá-la.

Realizar essa busca é prócero, pois enquanto membros de redes de apoio, os sujeitos podem sentir-se mais seguros e não retornarem aos profissionais de saúde com dúvidas ou queixas, satisfazendo-as entre membros de suas outras redes. No entanto, deste modo os profissionais podem desconhecer a evolução do sujeito e se as informações ofertadas estão corretas $^{(10)}$.

Isso não significa que o conhecimento perpassado por meio de redes sociais informais seja ultrapassado ou errôneo. Ao contrário, conhecimentos de cunho popular podem ser válidos e os profissionais têm que considerar a junção do conhecimento cientííco ao popular na busca pela autonomia dos sujeitos, sem preconceitos e abertos às novidades e incertezas.

"É nas certezas doutrinárias, dogmáticas e intolerantes que se encontram as piores ilusões" ${ }^{\prime \prime}(7: 86)$. Deve-se aprender a interpretar a realidade antes de apontar o que está certo ou errado. Não é fácil entendê-la. Tem-se, portanto, que buscar esse entendimento no sentido complexo, e compreender que o real é incerto, reconhecendo que há algo possível que ainda é invisível( ${ }^{(5,7)}$.

\section{INTER-RELAÇÕES - SUJEITO, FAMÍLIA, PROFISSIONAIS E SISTEMA}

O homem é um ser de relações e interações, dependente mesmo nos momentos de maior autonomia, contudo, "os mesmos laços e forças que unem os sujeitos para formar uma sociedade, também agem para separar e afastar, tudo é dependente das relações e interações dialógicas que se estabelecem"(6:254).

Interações e redes sociais de apoio que se constituem na situação do $C D$ não são menos complexas por se tratar de uma situação específica. Complexo é aquilo que foi tecido junto, quando elementos diferentes são inseparáveis na constituição do todo, quando há interdependência, interação e retroativação entre objeto e contexto, partes e o todo, o todo e as partes, assim como as partes entre $\mathrm{si}^{(7)}$.

A complexidade das interações no $C D$ envolve, de forma multidimensional, família, sujeito, profissional e sistema, em que cada um tem suas características individuais, mas compondo um todo, ou seja, simultaneamente unidade e multiplicidade. A família é unidade de cuidado para seus membros, contudo, além de cuidadora, também carece de cuidados para permanecer hígida e melhor desempenhar o cuidar ${ }^{(11,15-16)}$.

Assim como o sujeito, a família vivencia uma situação nova e precisa de conhecimentos e informações para lidar com as transformações que ocorrem $^{(12,16)}$. Nesse ínterim, a equipe de saúde atua como apoio às famílias, instrumentalizando-as para o cuidar.

O familiar/cuidador pode, no entanto, desenvolver uma relação de codependência com a situação de adoecimento. Buscar apoio em redes alternativas, tanto pode ser considerada por eles um benefício como um malefício, por desestabilizar as relações firmadas no domicílio.

Estabelecimento de vínculos e laços de compromisso e responsabilidade entre profissionais de saúde e população é característica principal do $\mathrm{CD}^{(14)}$. Mas isso não é tarefa simples, há barreiras como insegurança e fragilidade da família e ocupação de um espaço particular ${ }^{(14,16)}$. O que inicialmente pode ser positivo, no afastamento pode mostrar-se complicado, dificultando tanto ao profissional quanto ao sujeito/família, a quebra do vínculo sem gerar traumas.

Embora reconhecida a importância das redes sociais de apoio para o processo saúde-doença, quando o profissional adentra o domicílio passa a representar fonte de apoio social para os sujeitos. Ao indicar outra rede de apoio, tem uma ação que pode representar para os envolvidos uma forma de repassar o problema e não de resolvê-lo.

Contudo, essa é uma visão restritiva, pois isso não exime o profissional de seu papel nesse processo. Assim há aproximação do pensamento complexo que não reduz o todo a pequenas partes, mas as inclui; que reconhece fenômenos multidimensionais em vez de isolá-los e percebe que a realidade 
é simultaneamente conflituosa e solidária(8).

Alguns aspectos éticos são considerados na relação dos profissionais envolvidos no $C D$ com os sujeitos: dificuldade em estabelecer limites da relação profissional; pré-julgamento por parte da equipe e elaboração de prescrições que não se enquadram à realidade do contexto domiciliar ${ }^{(14)}$. Esses aspectos revelam falta de ética da compreensão, entendida como a "arte de viver que nos demanda, em primeiro lugar, compreender de modo desinteressado"(7:99).

Uma compreensão ampla permitirá reconhecer limites da intervenção profissional na vida dos sujeitos, o que, devido à acessibilidade, é mais difícil no CD. O domicílio permite aos profissionais maior interferência no estilo de vida de quem cuidam, mas ainda assim existem limites que devem ser esclarecidos em uma construção conjunta com quem vivencia.

Há possibilidade de acesso dos profissionais de saúde a informações relativas à vida doméstica familiar e conjugal(14). Isso tem vantagens por viabilizar atuação direcionada aos problemas, mas, simultaneamente, cria o problema da invasão de privacidade. Há dificuldades em manter a intimidade nos atendimentos em domicílio devido à presença de terceiros, o que dificulta o compartilhamento das informações particulares do sujeito com as pessoas envolvidas no cuidado $^{(14,15)}$.

A quebra da privacidade muitas vezes acontece por problemas de estrutura física ou devido às rotinas nas unidades de saúde ${ }^{(14)}$. Há ainda problemas organizacionais relativos à tomada de responsabilidade dos serviços por territórios, excesso de famílias adscritas por equipe e restrição do acesso dos sujeitos aos serviços ${ }^{(14)}$. É necessário refletir se esse modelo é justo e efetivo, pois quem precisa nem sempre é atendido.

Ressalta-se que a integração entre setores governamentais, tanto nos níveis micro como macro, representa fator influente para um cuidado de saúde efetivo ${ }^{(12)}$. Além disso, faz-se necessário superar o modelo biomédico, não dicotomizando a atenção individual da saúde coletiva ${ }^{(12,14)}$.

\section{CONCLUSÕES}

Buscou-se refletir, à luz do pensamento complexo, aspectos éticos que permeiam redes sociais de apoio no $C D$. Acreditase que esse campo de trabalho, por suas peculiaridades, exige um perfil modificado do enfermeiro, além de requerer maiores estudos, atualizações e reflexões, para ampliar o conhecimento dessa área.

Constatou-se que sujeito, família e profissionais podem ser considerados unidades complexas e que ao se articularem e se organizarem formam um sistema que deverá ser compreendido na relação que mantêm com o ambiente e tempo.

Espera-se que essa reflexão possibilite tornar mais factível o entendimento de que o ser humano é um homo complexus, ao mesmo tempo singular e plural, racional e irracional, biológico e cultural. Isso possibilitaria aos profissionais da saúde compreender e atuar em toda complexidade que envolve sujeito, sociedade e espécie humana.

\section{Referências}

1. Mendonça CS. Saúde da família, agora mais do que nunca! Cien Saúde Colet. 2009;14(Supl. 1):1493-7.

2. Gomes IM, Kalinowski LC, Lacerda MR, Ferreira RM. The domiciliary health care and its state of art: a bibliographic study [Internet]. [citado em 2011 Jun 03]. Disponível em: http://www.objnursing.uff.br/index.php/nursing/article/ view/j.1676-4285.2008.1781/411

3. Catafesta F, Lacerda MR. Skills of nurses needed for the development of home care: reflection [Internet]. [citado em 2011 Jun 03]. Disponivel em: http://www. objnursing.uff.br/index.php/nursing/article/view/j.1676-4285.2008.1302/345 4. Gomes IM, Lacerda MR. Correlations between social support and the home nursing - Integrative review [Internet]. [citado em 2011 Jun 03]. Disponivel em: http://www.objnursing.uff.br/index.php/nursing/article/ view/j.1676-4285.2010.2876/658

5. Morin E, Ciurana ER, Motta RD. Educar na era planetária: o pensamento complexo como método de aprendizagem pelo erro e incerteza humana. São Paulo: Cortez; Brasilia: UNESCO; 2003.

6. Koerich MS, Erdmann A, Nitschke RS. Ética em saúde: complexidade,

sensibilidade e envolvimento. Rev Bioethikos. 2009;3(2):252-5.

7. Morin E. Os sete saberes necessários à educação do futuro. 10ª ed. São Paulo: Cortez; Brasilia: UNESCO; 2005.

8. Morin E. A cabeça bem feita: repensar a reforma, reformar o pensamento. $17^{a}$ ed. Rio de Janeiro: Bertrand Brasil; 2010.

9. Morin E. Introdução ao pensamento complexo. 3a ed. Porto Alegre: Sulina; 2007.

10. Andrade GRB, Vaitsman J. Apoio social e redes: conectando solidariedade e saúde. Ciên Saúde Coletiva. 2002;7(4):925-34.

11. Santos LR, Leon CGRMP, Funghetto SS. Princípios éticos como norteadores no cuidado domiciliar. Ciên Saúde Coletiva. 2011;16(Supl. 1): 855-63.

12. Machado MFAS, Monteiro EMLM, Queiroz DT, Vieira NFC, Barroso MGT.

Integralidade, formação de saúde, educação em saúde e as propostas do SUS:

uma revisão conceitual. Ciên Saúde Coletiva. 2007;12(2):335-42.

13. Kerber NPC, Kirchhof ALC, Ceza-Vaz MR. Atenção domiciliária e direito

à saúde: uma experiência na rede pública brasileira. Acta Paul Enferm.

2010;23(2):244-50.

14. Zoboli ELCP. Bioética e atenção básica: um estudo de ética descritiva

com enfermeiros e médicos do Programa Saúde da Família [tese]. São Paulo:

Faculdade de Saúde Pública da Universidade de São Paulo; 2003.

15. Pérez-Cárceles $M D$, Pereñiguez JE, Osuna E, Luna A. Balancing confidentiality and the information provided to families of patients in primary care. J Med Ethics. 2005;31(9):531-5.

16. Lacerda MR, Oliniski SR. Familiares interagindo com a enfermeira no contexto domiciliar. Rev Gaúch Enferm. 2005;26(1):76-87. 